\title{
Static and dynamic compressive properties of ultra-high performance concrete (UHPC) with hybrid steel fiber reinforcements
}

\author{
Zemei $\mathrm{Wu}^{\text {a, b }}$, Caijun Shi ${ }^{a, *}$, Wen $\mathrm{He}^{\text {a }}$, Dehui Wang ${ }^{\text {a }}$ \\ ${ }^{a}$ College of Civil Engineering, Hunan University, Changsha 410082, China; \\ ${ }^{b}$ Department of Civil, Architectural and Environmental Engineering, Missouri University of Science and Technology, \\ Rolla, MO, 65401, USA
}

\begin{abstract}
Ultra-high performance concrete (UHPC) is promising in construction of concrete structures that suffer impact and explosive loads. In order to make UHPC structures more ductile and cost-effective, hybrid fiber reinforcements are often incorporated. In this study, a reference UHPC mixture with no fiber reinforcement and five mixtures with a single type of fiber reinforcement or hybrid steel fiber reinforcements of 6 and $13 \mathrm{~mm}$ in length at a total dosage of $2 \%$, by the volume of concrete, were prepared. Quasi-static compressive and flexural properties of those mixtures were investigated. Split Hopkinson press bar (SHPB) testing was adopted to evaluate their dynamic compressive properties under three impact velocities. Test results indicated that UHPC with $1.5 \%$ long fiber reinforcements and $0.5 \%$ short fiber reinforcements demonstrated the best static and dynamic mechanical properties. The static compressive and flexural strengths of UHPC with $2 \%$ long fiber reinforcements were greater than those with $2 \%$ short fiber reinforcements, whereas comparable dynamic compressive properties were observed. Strain rate effect was observed for the dynamic compressive properties, including peak stress, dynamic increase factor, and absorbed energy. The reinforcing mechanisms of hybrid fiber reinforcements in UHPC were eventually discussed.
\end{abstract}

*Corresponding author. Tel./fax: +86 73188823937.
E-mail address: zemianmian@gmail.com; cshi@ @hu.edu.cn (C. Shi) 
Keywords: Ultra-high performance concrete; Dynamic compressive properties; Hybrid fiber reinforcements; Static mechanical properties; Split Hopkinson press bar

\section{Introduction}

Ultra-high performance concrete (UHPC) was introduced in the mid-1990s [1]. Use of high content of cementitious materials, superplasticizer, steel fiber reinforcement, and special curing, such as heat and autoclave curing, and even nano-particles, are often mentioned in order to achieve high strength and toughness [1-4]. Compared to ordinary concrete, UHPC has a very high compressive strength in the order of $150 \mathrm{MPa}$ and a tensile strength in the order of $10 \mathrm{MPa}$ along with a strain hardening behavior $[5,6]$. Its superior performance allows its potential applications in military and protective structures that suffer impact and explosive loads with high impact velocity [7, 8]. However, the cost of steel fiber reinforcements used in UHPC is generally higher than that of the matrix. With the emphasis on sustainability of UHPC, minimizing the fiber reinforcement volume without sacrifice of its performance is of great significance [9]. Blending different types, shapes and/or sizes of fiber reinforcement has been proven as one of the effective methods because of a combination of various features from those different fiber reinforcements [10-12]. For example, the short fiber reinforcements can effectively restrict the development of micro-cracks while the long fiber reinforcements can bridge macro-cracks [9]. Research on the mechanical properties of hybrid fiber-reinforced UHPC has attracted a lot of attention, but most of the literature thus far was focused on quasi-static properties, such as compressive, tensile, and flexural properties, rather than dynamic behavior $[5,12,13]$.

There are two common methods, drop weight and split Hopkinson pressure bar (SHPB) testing, to measure the dynamic behavior of a composite material. The drop weight testing has the ability to 
reproduce conditions under which real life component would be subjected to impact loading [14]. Besides, replication of testing arrangement is possible by using this method. Habel et al. [6] employed this method to evaluate the impact bending performance of ultra-high performance fiber reinforced concrete (UHPFRC) and found that the strength increased with the increase of strain rate. Although this method is simple and easy to be implemented, the experimental results are greatly influenced by the specimen size and configuration, such as drop weight and speed, support stiffness, etc. [15, 16]. The SHPB testing is the most commonly used one for evaluating dynamic properties [17, 18]. Rong et al. [19] used the SHPB testing to investigate the dynamic compression behavior of UHPFRC with different fiber reinforcement volumes and found that the impact resistance of UHPFRC was improved with the increase of fiber reinforcement volume. Under the same compressive loading, the control specimens were crushed, while those with $3 \%$ or $4 \%$ of steel fiber reinforcements remained essentially intact. Lai et al. [20] indicated that the peak stress, peak strain, and the area under strain-stress curve of UHPFRC increased with the increase of strain rate. Zhang et al. [21] reported that the dynamic tensile strength of C200 green reactive powder concrete increased markedly with the increase of impact velocity, ranging from 4 to $14 \mathrm{~m} / \mathrm{s}$. Until now, no information can be found about the effect of fiber hybridization on the dynamic mechanical properties, especially on the dynamic compressive properties of UHPC.

This research aims at investigating the influences of hybrid steel fiber reinforcements with lengths of 13 and $6 \mathrm{~mm}$ on flowability, quasi-static compressive and flexural properties, as well as dynamic compressive behavior of UHPC. Split Hopkinson pressure bar testing was conducted to characterize the dynamic compressive behavior, including failure pattern, load-deflection curve, peak stress, and fracture energy, under three high impact velocities. Dynamic increase factor was introduced to compare the quasi-static properties with the dynamic compressive properties. Finally, the reinforcing mechanisms of hybrid fiber reinforcements in UHPC were discussed. 


\section{Materials and experimental program}

\subsection{Materials}

Portland cement (P.I 42.5) complying with the Chinese Standard GB175-2007 was used [22]. Table 1 summarizes the chemical composition and density of the cement, silica fume, and slag. Silica fume has an average particle size of 0.1 to $0.2 \mu \mathrm{m}$ and a specific surface area of $18,500 \mathrm{~m}^{2} / \mathrm{kg}$. Slag has a specific area of $410 \mathrm{~m}^{2} / \mathrm{kg}$. Two straight smooth steel fibers with diameters of $0.2 \mathrm{~mm}$ but one with a length of $6 \mathrm{~mm}$ and the other one of $13 \mathrm{~mm}$ were used. The tensile strength is 2,800 MPa. River sand with a maximum particle size of $2.36 \mathrm{~mm}$ was used. A polycarboxylate-based superplasticizer (SP) with a solid content of $20 \%$ was used.

Table 1 Chemical composition and density of cementitious materials

\begin{tabular}{ccccccccccc}
\hline $\begin{array}{c}\text { Chemical } \\
\text { composition }\end{array}$ & $\begin{array}{c}\mathrm{CaO} \\
(\%)\end{array}$ & $\begin{array}{c}\mathrm{SiO}_{2} \\
(\%)\end{array}$ & $\begin{array}{c}\mathrm{Al}_{2} \mathrm{O}_{3} \\
(\%)\end{array}$ & $\begin{array}{c}\mathrm{Fe}_{2} \mathrm{O}_{3} \\
(\%)\end{array}$ & $\begin{array}{c}\mathrm{SO}_{3} \\
(\%)\end{array}$ & $\begin{array}{c}\mathrm{MgO} \\
(\%)\end{array}$ & $\begin{array}{c}\mathrm{Na}_{2} \mathrm{O}_{\mathrm{eq}} \\
(\%)\end{array}$ & $\begin{array}{c}\mathrm{K}_{2} \mathrm{O} \\
(\%)\end{array}$ & $\begin{array}{c}\mathrm{C} \\
(\%)\end{array}$ & $\begin{array}{c}\text { Density } \\
\left(\mathrm{kg} / \mathrm{m}^{3}\right)\end{array}$ \\
\hline Cement & 62.49 & 21.18 & 4.73 & 3.41 & 2.83 & 2.53 & 0.56 & - & - & 3,110 \\
Silica fume & 1.85 & 93.90 & - & 0.59 & - & 0.27 & 0.17 & 0.86 & 1.06 & 2,150 \\
Slag & 39.11 & 33.00 & 13.91 & 0.82 & - & 10.04 & - & - & - & 2,900 \\
\hline
\end{tabular}

\subsection{Mixture proportion}

Based on the previous study $[23,24]$, UHPC with a water to binder ratio (w/b) of 0.18 and silica fume content of $20 \%$ to $25 \%$, by mass of cementitious materials, can obtain a satisfactory bond to steel fiber reinforcement and mechanical properties. Therefore, UHPC mixture with a w/b of 0.18 and silica fume content of $25 \%$ was used in this study. The SP dosage was fixed at $2 \%$ by the mass of the binder. To investigate the hybridization of short and long fiber reinforcements on quasi-static and dynamic properties of UHPC, a reference mixture with no fiber reinforcement and five mixtures with a single type of fiber reinforcement or hybrid fiber reinforcements at a total content of $2 \%$, by volume of the concrete, were used. Table 2 shows the five mixture proportions. LOSO was the reference mixture with no fiber 
reinforcement. L1.5S0.5 was referred to the mixture with $1.5 \%$ long fiber reinforcements and $0.5 \%$ short fiber reinforcements.

Table 2 Mixture proportions of UHPC

\begin{tabular}{ccccccccc}
\hline No. & $\begin{array}{c}\text { Cement } \\
\left(\mathrm{kg} / \mathrm{m}^{3}\right)\end{array}$ & $\begin{array}{c}\text { Slag } \\
\left(\mathrm{kg} / \mathrm{m}^{3}\right)\end{array}$ & $\begin{array}{c}\text { Silica } \\
\text { fume } \\
\left(\mathrm{kg} / \mathrm{m}^{3}\right)\end{array}$ & $\begin{array}{c}\text { Sand } \\
\left(\mathrm{kg} / \mathrm{m}^{3}\right)\end{array}$ & $\begin{array}{c}\text { Water } \\
\left(\mathrm{kg} / \mathrm{m}^{3}\right)\end{array}$ & $\begin{array}{c}\text { Superplasticizer } \\
\left(\mathrm{kg} / \mathrm{m}^{3}\right)\end{array}$ & $\begin{array}{c}\text { Long } \\
\text { fiber } \\
(\%)\end{array}$ & $\begin{array}{c}\text { Short } \\
\text { fiber } \\
(\%)\end{array}$ \\
\hline L0S0 & 472 & 315 & 262 & 1,049 & 178 & 21 & 0 & 0 \\
L2S0 & 472 & 315 & 262 & 1,049 & 178 & 21 & 2.0 & 0 \\
L1.5S0.5 & 472 & 315 & 262 & 1,049 & 178 & 21 & 1.5 & 0.5 \\
L1S1 & 472 & 315 & 262 & 1,049 & 178 & 21 & 1.0 & 1.0 \\
L0.5S1.5 & 472 & 315 & 262 & 1,049 & 178 & 21 & 0.5 & 1.5 \\
L0S2 & 472 & 315 & 262 & 1,049 & 178 & 21 & 0 & 2.0 \\
\hline
\end{tabular}

\subsection{Mixing procedure and sample preparation}

During mixing, dry powders, including cement, silica fume, slag, and river sand, were first mixed for $3 \mathrm{~min}$ at a high speed. Water and superplasticizer were then added and mixed for approximately 6 min at a low speed. Steel fiber reinforcements were slowly added and mixed for another 6 min until achieving a uniform distribution.

All the mixtures were cast into molds for the testing of flowability and mechanical properties. Specimens were then kept in a room at $20^{\circ} \mathrm{C}$ and relative humidity $(\mathrm{RH})$ greater than $95 \%$ for approximately $24 \mathrm{~h}$. They were then demolded and cured in lime-saturated water at $20^{\circ} \mathrm{C}$ for 7 and $28 \mathrm{~d}$.

\subsection{Experimental methods}

\subsubsection{Flowability}

The flowability of all mixtures was measured in accordance with the Chinese Standard GB/T 2419-2005 [25]. The mixtures were cast into a mini cone mold and jolted for 25 times. Two diameters perpendicular to each other were determined and mean values were reported. 


\subsubsection{Static mechanical properties}

Specimens of $40 \times 40 \times 160 \mathrm{~mm}$ were cast for determination of static compressive and flexural strengths. Three samples of each batch were tested. The flexural and compressive strengths measurements were conducted according to GB/T 17671-1999 (similar to ISO 697:1989) [26]. Three-point bending testing was first performed to obtain flexural properties. Six broken specimens measuring $40 \times 40 \times 40$ $\mathrm{mm}$ were then tested for compressive strength. Two non-casting surfaces of the specimen were used as a bottom and a top surface to ensure complete contact with the platen of the machine. The loading rate was set at $2.4 \mathrm{kN} / \mathrm{s}$. Averages over three samples for flexural strength and over six samples for compressive strength were reported.

\subsubsection{Split Hopkinson pressure bar (SHPB) testing}

A schematic illustration of SHPB testing equipment is shown in Fig. 1. The testing is based on the theory of one-dimensional wave propagation in an elastic bar [27]. The specimen is placed between the ends of the input and output bars. A stress wave is created and propagates through the bar toward the specimen at the end of the input bar. This incident wave then splits into a transmitted wave and a reflected wave upon reaching the specimen. The transmitted wave travels through the specimen and goes into the output bar, causing plastic deformation in the specimen. The reflected wave is reflected away from the specimen and travels back to the input bar. The whole process is recorded through a computer.

The SHPB equipment used in this research is made of superior alloy steel with a diameter of $100 \mathrm{~mm}$. The lengths of the input and output bars are 6,000 and $4,000 \mathrm{~mm}$, respectively. The distances of strain gauge on the input and output bars to the specimen are 3,000 and 1,000 mm, respectively. The length of the striker bar is 1,500 mm. Cylinder samples with a diameter of $92 \mathrm{~mm}$ and a height of $46 \mathrm{~mm}$ were used. Before testing, the two ends of each specimen were ground to make them parallel so as to ensure the 
reliability of the results.

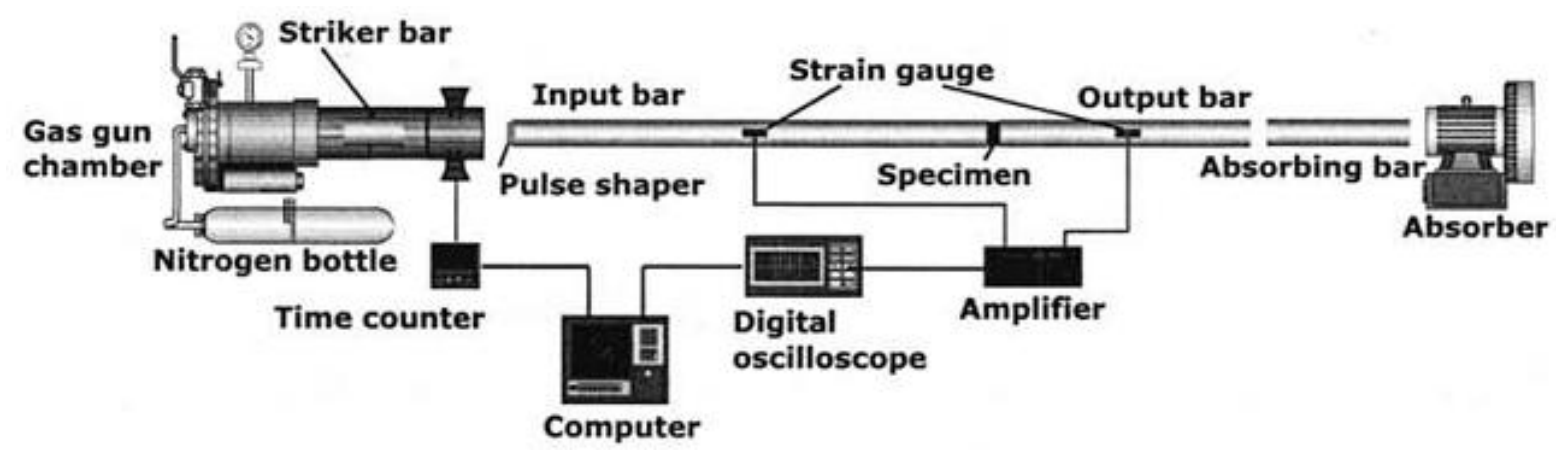

(a) Schematic illustration of SHPB equipment [28]

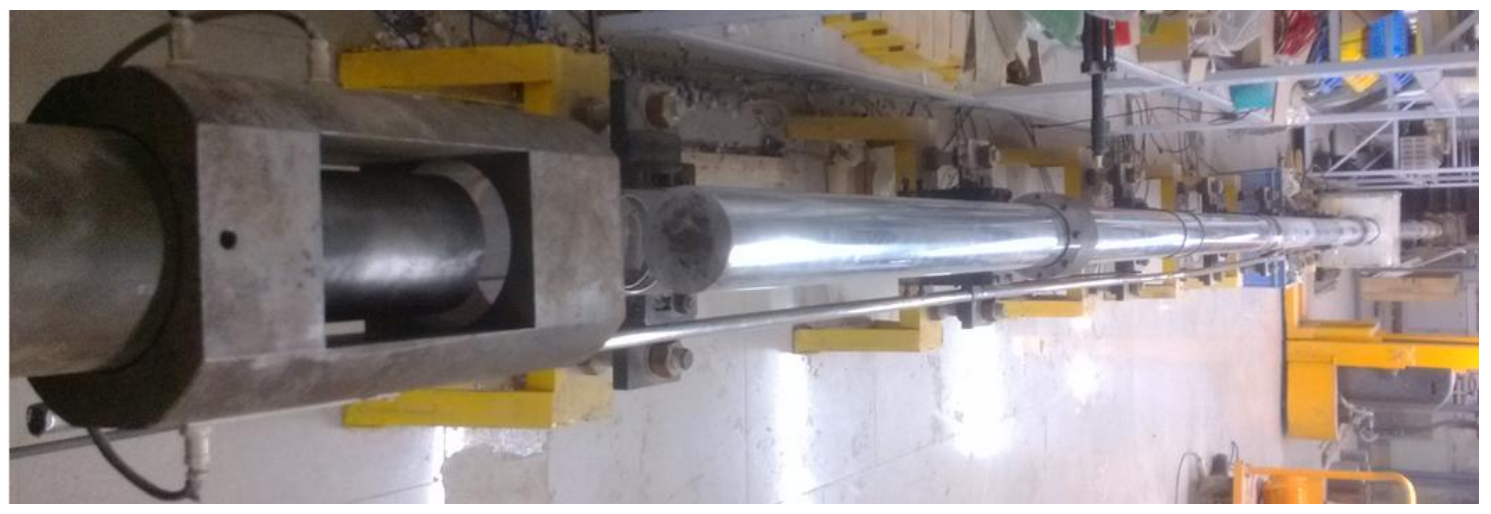

(b) Picture of SHPB equipment

Fig. 1 SHPB testing equipment

\section{Results and discussion}

\subsection{Effects of hybrid steel fiber reinforcements on flowability of UHPC}

Figure 2 shows the effects of hybrid fiber reinforcements on flowability of the UHPC mixtures. The UHPC mixture with no steel fiber reinforcement had the highest flowability of $248 \mathrm{~mm}$. With the incorporation of a single type of fiber reinforcement or hybrid fiber reinforcements, the flowability decreased. This agrees well with the results reported by Yu et al. [29]. The reduced flowability associated with the fiber reinforcements was attributed to the following reasons [30, 31]: (1) fiber reinforcements are much more elongated and have higher surface area compared to aggregates, which can increase the cohesive force; (2) steel fiber reinforcements can alter the granular skeleton structure and hinder the flow of fresh paste; (3) steel fiber reinforcements tends to be perpendicular to the flow direction, generating 
resistance force and moment to the flow velocity of fresh mixtures.

It can be also observed from Fig. 2, the UHPC mixtures with the hybrid fiber reinforcements demonstrated higher flowability than those with the single type of fiber reinforcement. The higher the short fiber reinforcement volume in the UHPC mixture with hybrid fiber reinforcements was, the better the flowability was. However, when all the $2 \%$ long fiber reinforcements were replaced by the short fiber reinforcement, the mixture (LOS2) obtained the worst flowability. In the case of hybrid fiber reinforcements, the mutual effects between the short and long fiber reinforcements can restrict each other's rotation to avoid the perpendicular orientation to the flow direction [29-31]. This can reduce the resistance force to some extent, and eventually enhance the flowability when compared to those with the single type of fiber reinforcement (L2S0 and L0S2 mixtures). The worst flowability of the L0S2 mixture might be attributed to the increase in fiber reinforcement volume associated with short length.

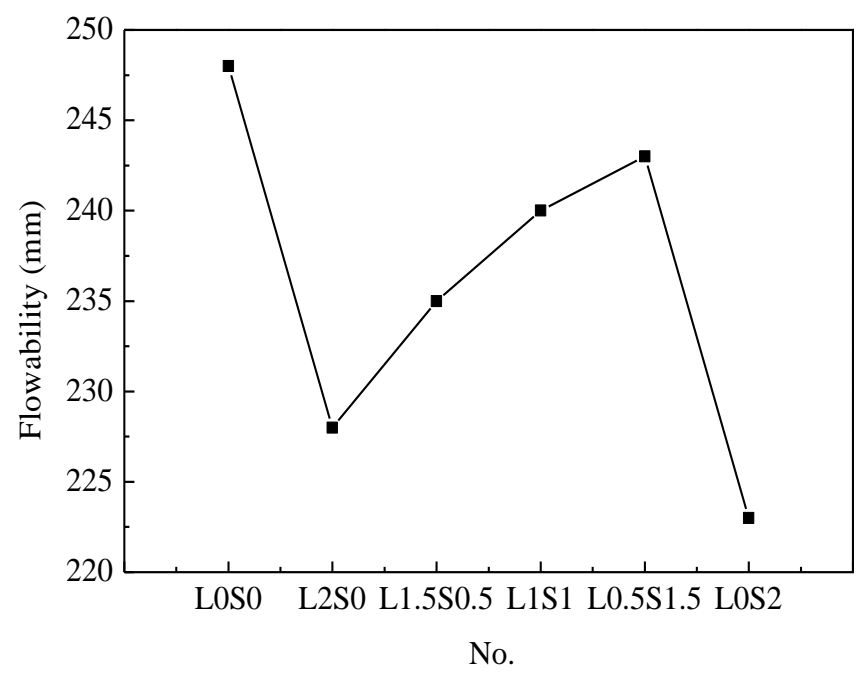

Fig. 2 Effects of hybrid fiber reinforcements on flowability of UHPC

3.2. Effects of hybrid fiber reinforcements on static compressive and flexural strengths

The effects of hybrid fiber reinforcements on static compressive strength of UHPC are illustrated in Fig. 3. The 7- and 28-d static compressive strengths of the reference UHPC mixture (L0S0) were 81.1 and 98.3 MPa, respectively. It increased obviously with the incorporation of steel fiber reinforcements. The 
compressive strengths of the L2S0 mixture at 7 and $28 \mathrm{~d}$ were increased by $35 \%$ and $28 \%$, respectively, in comparison to the reference mixture. For the mixtures with hybrid fiber reinforcements, the compressive strength increased first but then decreased with the increase of the short fiber reinforcement volume. When $1.5 \%$ long fiber reinforcements and $0.5 \%$ short fiber reinforcements were used, the highest compressive strength was achieved. Besides, the static compressive strength of the L2S0 mixture was obviously greater than that of the L0S2 mixture. The decrease in compressive strength with the increase of short fiber reinforcement content might be due to the lower efficiency of short fiber reinforcements in restricting the development of cracks $[11,12,29]$. Therefore, the use of $2 \%$ hybrid fiber reinforcements could increase the static compressive strength by $20 \%$ to $40 \%$ compared to the reference mixture.

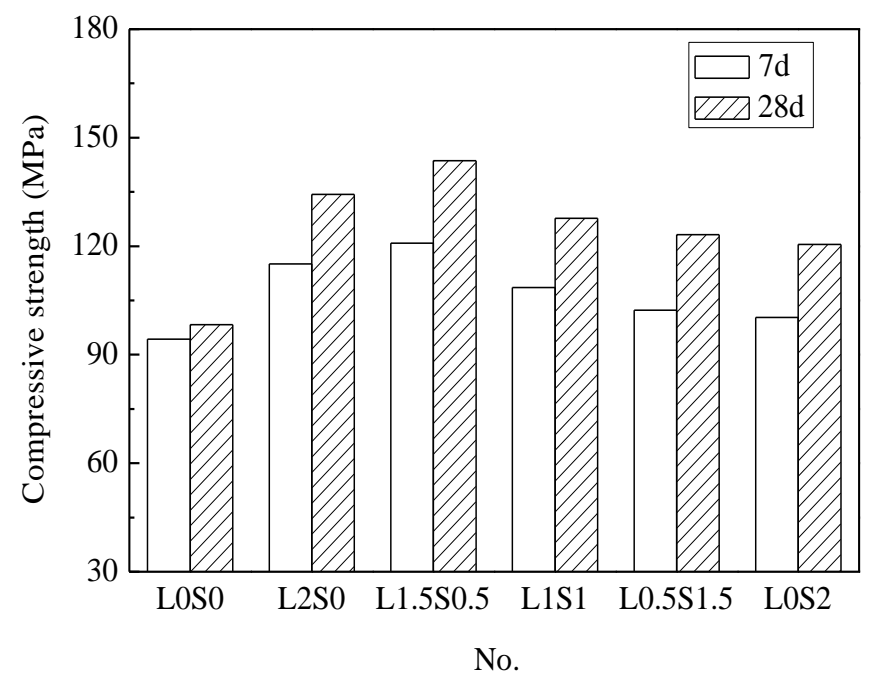

Fig. 3 Effects of hybrid fiber reinforcements on static compressive strength of UHPC

Figure 4 depicts the effects of hybrid fiber reinforcements on static flexural behavior of UHPC. The UHPC reference specimens with no fiber reinforcement showed a sudden drop of load when reaching the initial cracking point at a deflection of $0.25 \mathrm{~mm}$, as observed from Fig. 4(a). UHPC specimens with fiber reinforcement could continue to sustain load after the initial cracking until they reached the peak load. The volume of long and short fiber reinforcements had a significant effect on the peak load. The L1.5S0.5 mixture was shown to exhibit the greatest peak load, followed by the L2S0 mixture. As can be also 
observed from Fig. 4(a), the load-deflection curves showed obvious zigzag patterns after the peak load.

This is consistent with the results in literature [11]. It was observed that there were tearing sounds after the peak load, which indicates that the fiber reinforcements were continuously pulled out from the matrix.

The change in static ultimate flexural strength of UHPC with hybrid fiber reinforcements showed a similar trend to that of the static compressive strength, as illustrated in Fig. 4(b). The L1.5S0.5 mixture showed the highest flexural strength of $32 \mathrm{MPa}$ at $28 \mathrm{~d}$, which increased by $108 \%$ compared to the reference mixture. This might be due to the combined strengthening effects from the short and long fiber reinforcements, which can restrict the crack development in two length scales, both in a scale of $6 \mathrm{~mm}$ and $13 \mathrm{~mm}$ length [12]. However, when more long fiber reinforcements were replaced by short fiber reinforcements, the flexural strength decreased. The LOS2 mixture obtained the worst static flexural strength among the five UHPC mixtures with fiber reinforcement.

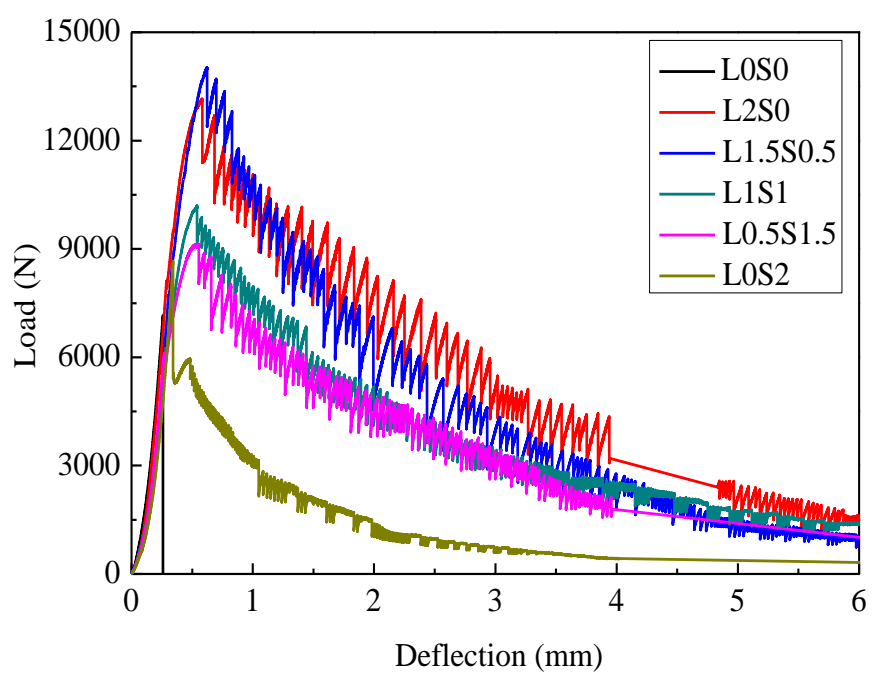

(a) Flexural load-deflection curves at $28 \mathrm{~d}$

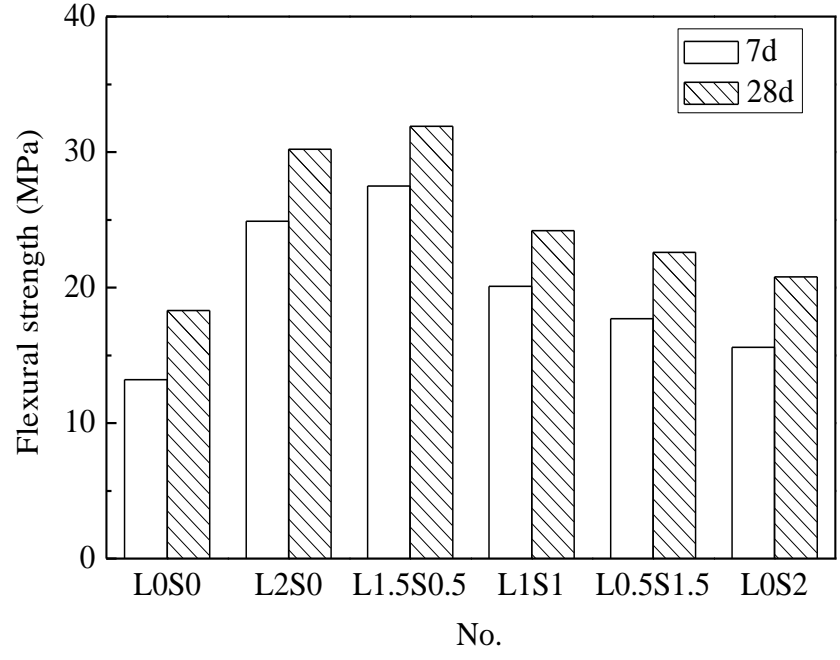

(b) Flexural strengths at 7 and $28 \mathrm{~d}$

Fig. 4 Effects of hybrid fiber reinforcements on flexural behavior of UHPC

3.3. Effects of hybrid fiber reinforcements on dynamic compressive properties of UHPC

3.3.1. Effects of hybrid fiber reinforcements on dynamic failure pattern of UHPC

Figure 5 illustrates the dynamic failure pattern of UHPC with and without fiber reinforcement at $28 \mathrm{~d}$.

At the impact velocity of $8.9 \mathrm{~m} / \mathrm{s}$, all the specimens exhibited a failure mode of pulverization. The 
reference mixture (LOS0) with no fiber reinforcement showed a large quantity of small and irregular broken concrete fragments. The use of steel fiber reinforcements could effectively restrict the transverse deformation of specimens. As can be seen from Fig. 5(b-d), the sizes of the broken fragments of the UHPC specimens varied with the hybrid fiber reinforcement volumes. The L2S0 mixture showed relative large and round broken fragments. For the L1.5S0.5 mixture, balanced broken fragments with both large and small parts could be observed. Many embedded fiber reinforcements were observed in the fracture surface, bridging the small fragments. However, relatively small and elongated broken fragments were observed for the L0S2 mixture, as can be observed from Fig. 5(d).

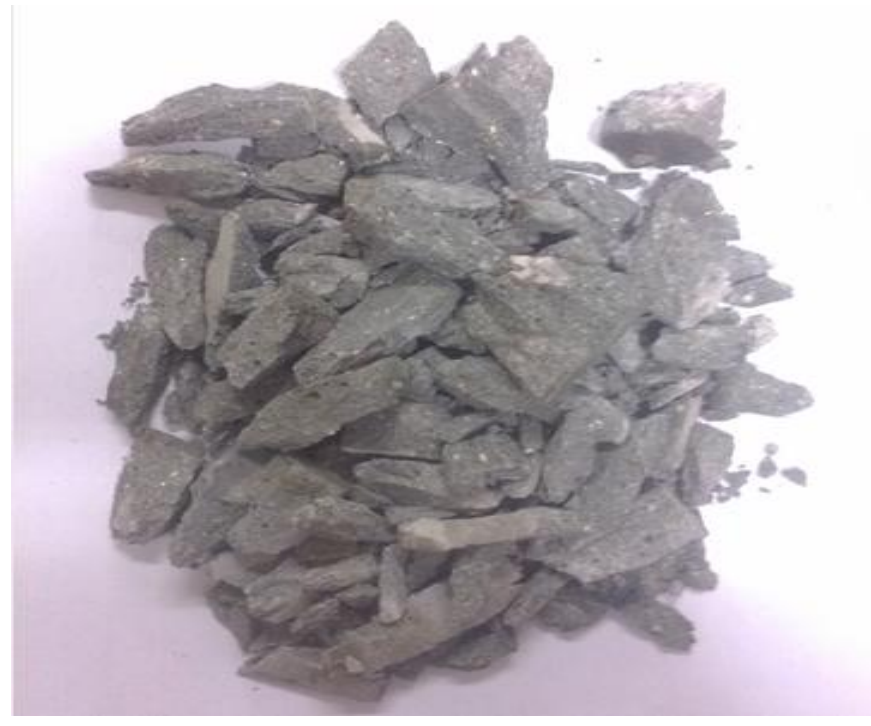

(a) LOS0 mixture

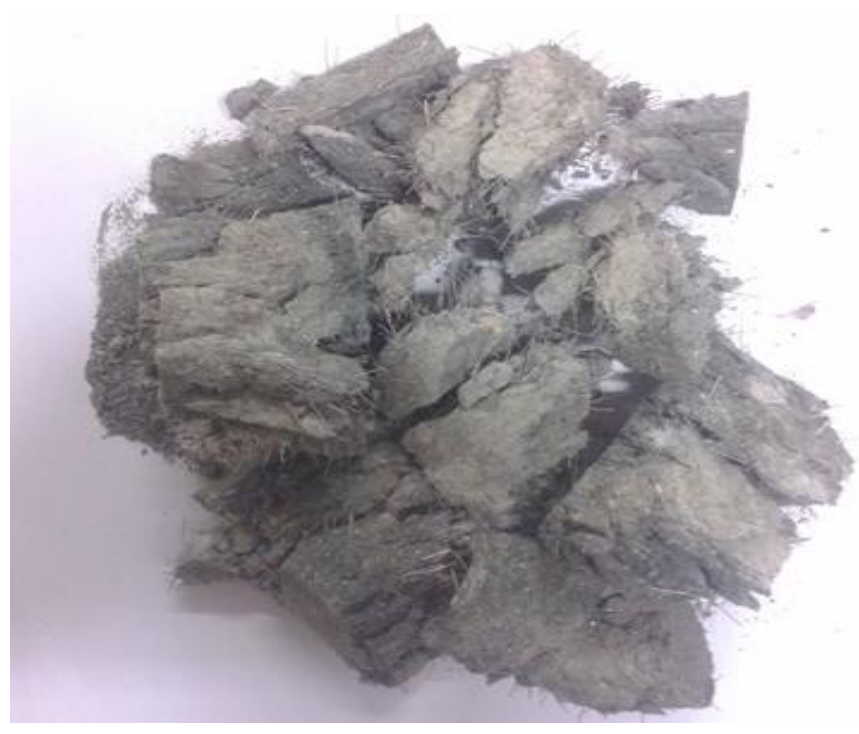

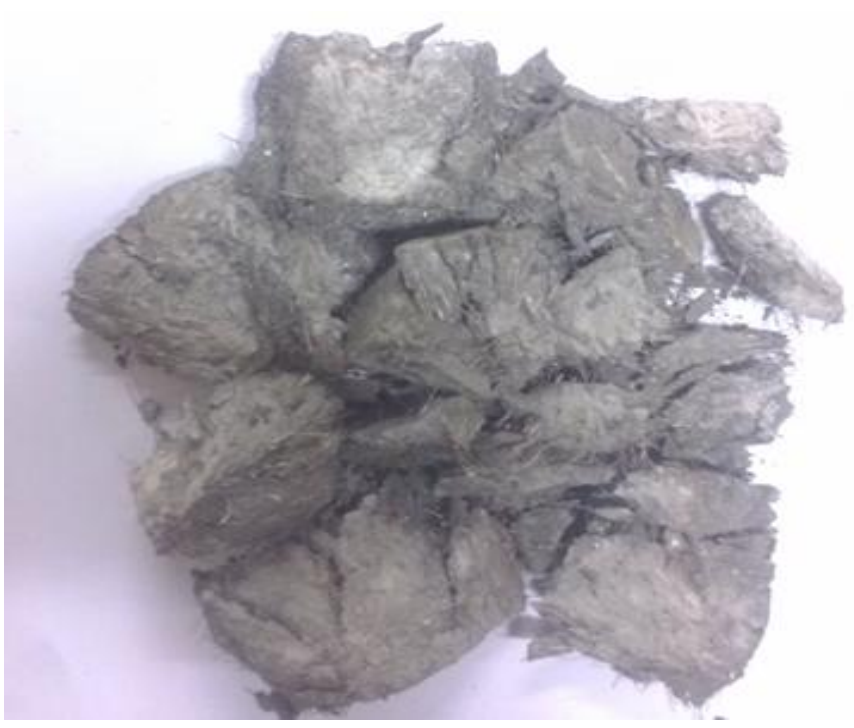

(b) L2S0 mixture

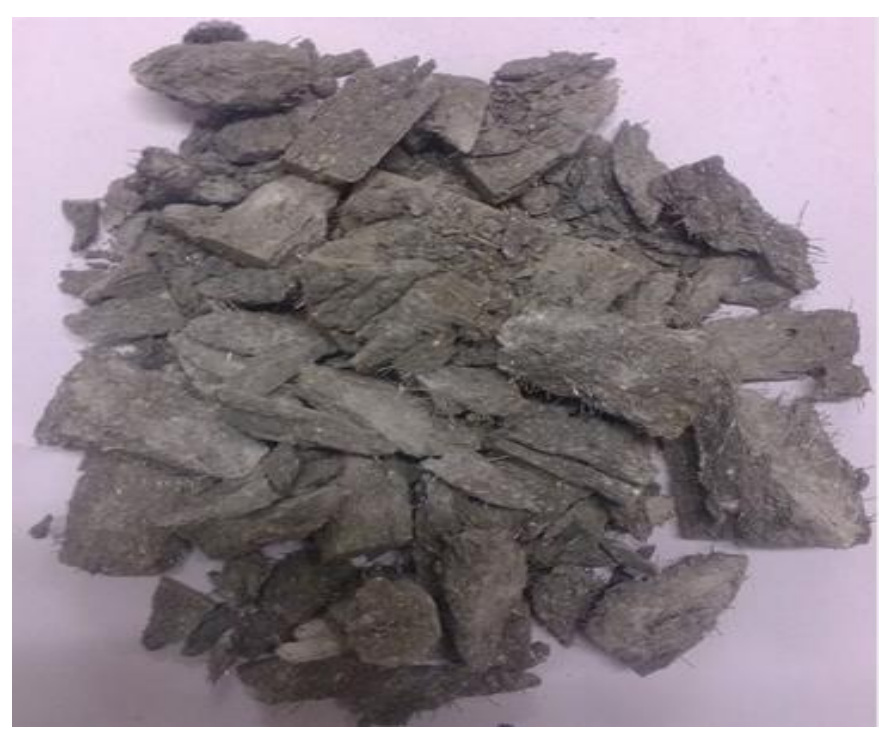

11 
Fig. 5 Effects of hybrid fiber reinforcements on dynamic failure patterns of UHPC at an impact velocity of $8.9 \mathrm{~m} / \mathrm{s}$

\subsubsection{Effects of strain rates on dynamic compressive load-deflection relationship of UHPC}

The effects of different strain rates on dynamic compressive load-deflection curves of UHPC with and without fiber reinforcement at $28 \mathrm{~d}$ are illustrated in Fig. 6. For all UHPC mixtures, the stress changed almost linearly with the strain up to the peak stress. Afterward, the stress-strain curves showed a decreasing branch. When the strain reached approximately 0.04 , a constant stress was observed.

From Fig. 6, it can be also seen that the dynamic compressive behavior of UHPC was sensitive to strain rate. All the mixtures showed a strain rate effect, that is, the peak stress increased with the increase of strain rate. The peak stress for the L2S0 mixture was 141.2 MPa at the strain rate of $115.5 \mathrm{~s}^{-1}$, and increased to 160.6 and $177.4 \mathrm{MPa}$, respectively, when the strain rate increased to 158.2 and $195.8 \mathrm{~s}^{-1}$. $\mathrm{Li}$ and Cotsovos $[17,32,33]$ proposed that this strain rate effect was due to lateral inertia associated with friction to the contact surface under rapid impact loading. Besides, the increasing rate for peak stress decreased gradually with the increase of strain rate. This might be attributed to the Stefan effect associated with the presence of free water in concrete [34].

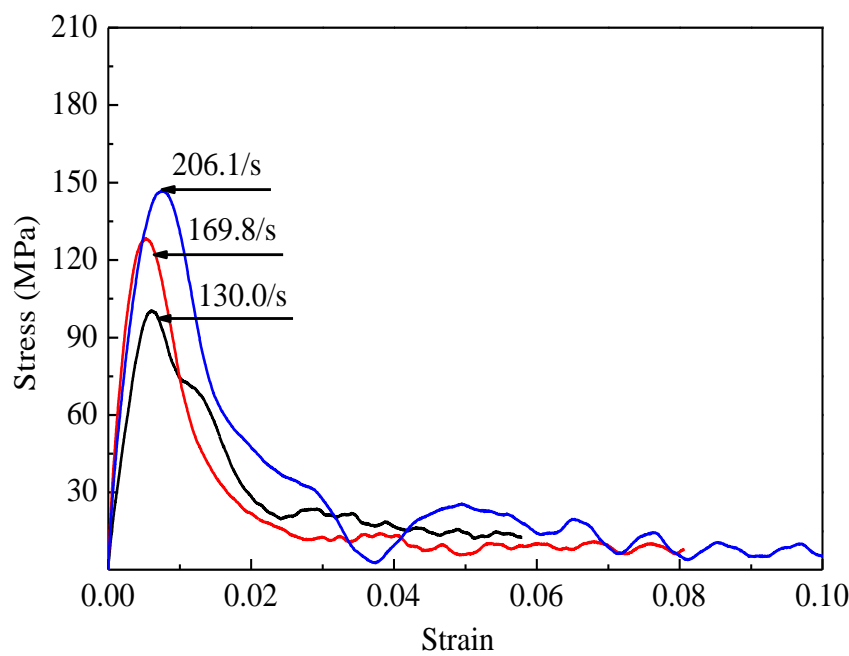

(a) LOS0

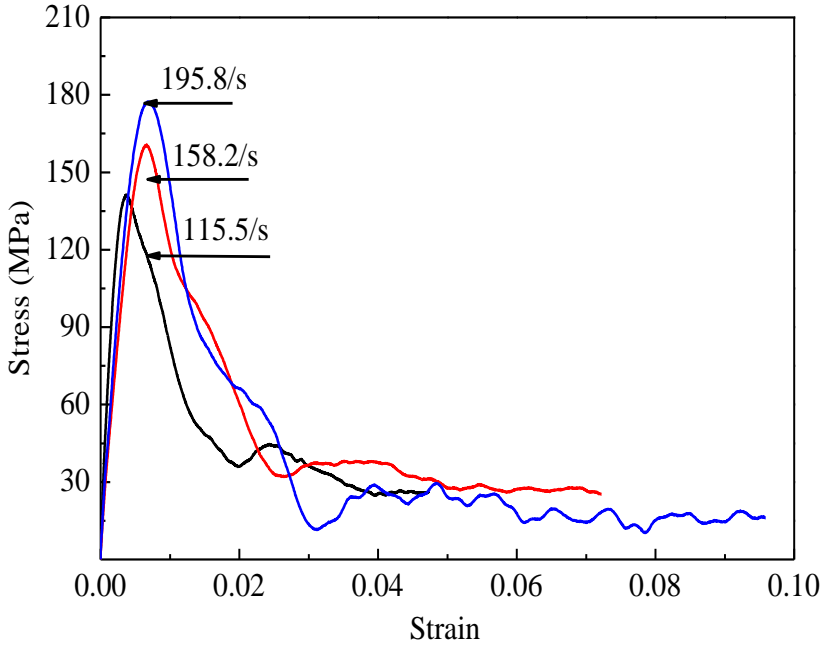

(b) L2S0 


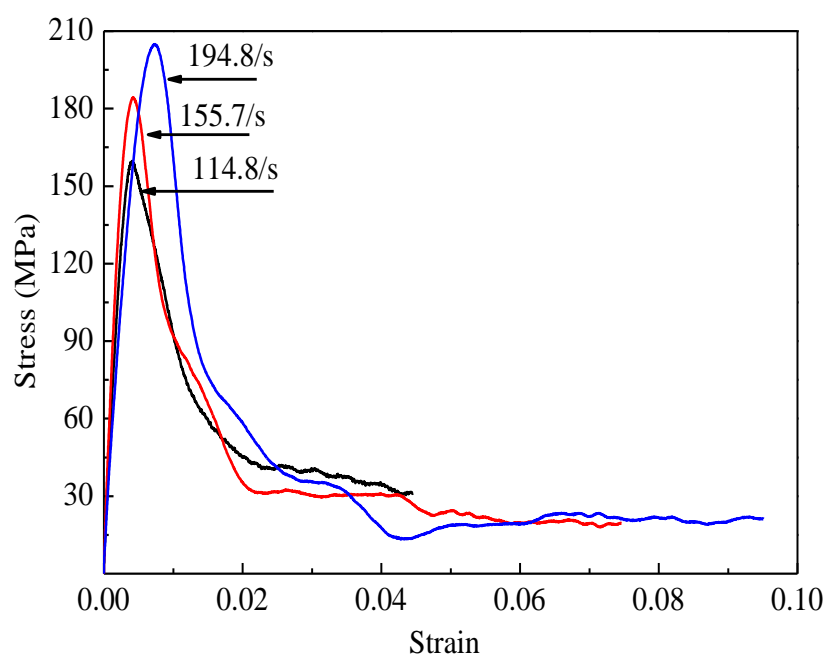

(c) L1.5S0.5

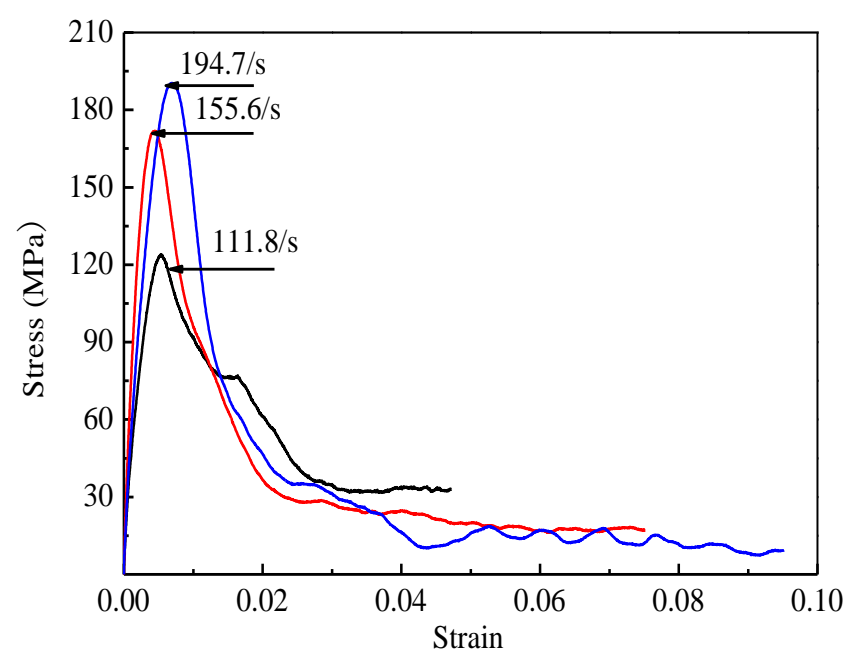

(e) L0.5S1.5

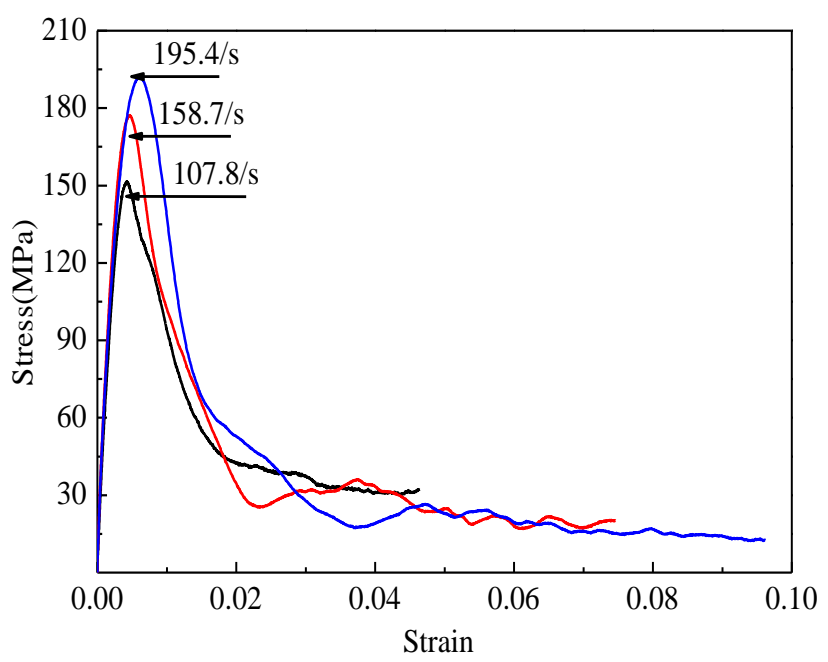

(d) L1S1

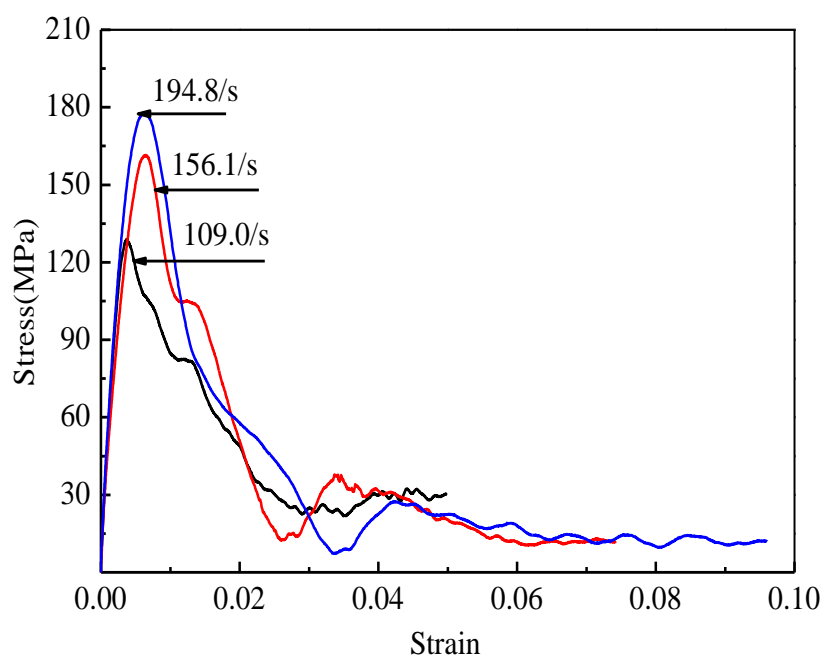

(f) LOS2

Fig. 6 Effects of strain rates on dynamic compression stress-strain curves of UHPC at $28 \mathrm{~d}$

The dynamic increase factor (DIF) was introduced to give a comparision between the quasi-static and dynamic compressive properties of UHPC, as summerized in Table 3. DIF is defined as the ratio of the dynamic compressive strength (peak stress) to the static compressive strength at curing age of $28 \mathrm{~d}$. An accurate DIF can ensure an appropriate stucture dimension design, reduced maximum amount of materials, and eventually enhanced energy efficiency and environmental protection [28].

As can be seen from Table 3, all the DIFs were larger than 1. This suggests the dynamic compressive strength was greater than the static compressive strength. Besides, the DIFs increased with the increase of 
strain rate. It is known that weak zones like pores and micro-cracks intrinsically exist in the UHPC specimens. Under static loading, there is enough time for only a few micro-cracks in local area to develop into macro-cracks, and eventually lead to failure of concrete. However, the loading time is extremely short under impact loading. Before one or two micro-cracks slowly propagate propogates into macro-cracks, more new micro-cracks have been nucleated and enlarged $[35,36]$. Such nucleation of a large number of cracks can consume more energy, and hence results in higher ultimate dynamic compressive strength. Moreover, the lateral confinement from both contact surface restriction and lateral inertia can also cause enhancement in dynamic strength during the rapid loading process [36].

The increased rate for DIF decreased with further increase of strain rate. This is consitent with the results in Ref. [36, 37]. Under low strain rate, cracks in concrete are limited in size and quantity, which can be efficiently prevented by the fiber reinforcements. However, a large quantity of cracks with increasing size would be induced at high strain rate, which is less efficient for fiber reinforcement to exert their influence.

Table 3 Summarization of static and dynamic compressive properties of UHPC at $28 \mathrm{~d}$

\begin{tabular}{|c|c|c|c|c|c|c|c|}
\hline No. & $\begin{array}{c}\text { Impact } \\
\text { velocity } \\
(\mathrm{m} / \mathrm{s})\end{array}$ & $\begin{array}{c}\text { Strain } \\
\text { rate } \\
\left(\mathrm{s}^{-1}\right)\end{array}$ & $\begin{array}{c}\text { Dynamic } \\
\text { compressive } \\
\text { strength } \\
(\mathrm{MPa})\end{array}$ & $\begin{array}{c}\text { Strain at } \\
\text { peak stress } \\
\left(\times 10^{-3}\right)\end{array}$ & $\begin{array}{c}\text { Static } \\
\text { compressive } \\
\text { strength } \\
(\mathrm{MPa})\end{array}$ & $\begin{array}{c}\text { Dynamic } \\
\text { increase } \\
\text { factor }\end{array}$ & $\begin{array}{c}\text { Fracture } \\
\text { energy } \\
\left(\mathrm{MJ} / \mathrm{m}^{3}\right)\end{array}$ \\
\hline \multirow{3}{*}{ LOSO } & 8.9 & 130.0 & 100.4 & 6.01 & 98.3 & 1.02 & 1.76 \\
\hline & 11.6 & 169.8 & 128.4 & 5.24 & 98.3 & 1.31 & 1.94 \\
\hline & 14.0 & 206.1 & 146.8 & 7.54 & 98.3 & 1.49 & 3.10 \\
\hline \multirow{3}{*}{$\mathrm{L} 2 \mathrm{~S} 0$} & 8.9 & 115.5 & 141.2 & 5.32 & 134.3 & 1.05 & 2.62 \\
\hline & 11.7 & 158.2 & 160.6 & 6.63 & 134.3 & 1.20 & 3.76 \\
\hline & 13.9 & 195.8 & 177.4 & 6.89 & 134.3 & 1.32 & 3.90 \\
\hline \multirow{3}{*}{ L1.5S0.5 } & 8.9 & 114.8 & 159.7 & 4.06 & 143.6 & 1.11 & 2.72 \\
\hline & 11.7 & 155.7 & 184.3 & 4.22 & 143.6 & 1.28 & 3.29 \\
\hline & 13.9 & 194.8 & 204.8 & 7.38 & 143.6 & 1.43 & 4.15 \\
\hline \multirow{3}{*}{ L1S1 } & 8.9 & 107.8 & 151.5 & 4.28 & 127.7 & 1.19 & 2.59 \\
\hline & 11.7 & 158.7 & 177.2 & 4.67 & 127.7 & 1.39 & 3.27 \\
\hline & 14.0 & 195.4 & 192.0 & 6.17 & 127.7 & 1.50 & 3.88 \\
\hline \multirow{2}{*}{ L0.5S 1.5} & 8.9 & 111.8 & 124.0 & 3.76 & 123.2 & 1.01 & 2.41 \\
\hline & 11.6 & 155.6 & 171.8 & 4.50 & 123.2 & 1.39 & 3.17 \\
\hline
\end{tabular}




\begin{tabular}{lccccccc}
\hline & 13.9 & 194.7 & 190.4 & 6.87 & 123.2 & 1.55 & 3.61 \\
\hline \multirow{2}{*}{ L0S2 } & 8.8 & 109.0 & 128.8 & 3.69 & 120.5 & 1.07 & 2.36 \\
& 11.6 & 156.1 & 161.5 & 6.48 & 120.5 & 1.34 & 3.06 \\
& 13.9 & 194.8 & 177.9 & 6.17 & 120.5 & 1.48 & 3.50 \\
\hline
\end{tabular}

3.3.3. Effects of hybrid fiber reinforcements on dynamic compressive load-deflection relationship of UHPC

Figure 7 compares the dynamic compression stress-strain curves of UHPC with hybrid steel fiber reinforcements under the same impact velocity. The reference mixture LOSO showed the lowest dynamic compressive strength and toughness, whereas the L1.5S0.5 mixture exhibited the highest corresponding values followed by the L1S1 mixture and then the L0.5S1.5 mixture. This agrees well with the results of static compressive properties. Moreover, the UHPC mixtures with the single type of fiber reinforcement (L0S2 and L2S0 mixtures) had comparable dynamic peak stress. Besides, the dynamic compressive peak stress was higher than that of the static compressive strength, especially at higher impact velocity.

As we know, the impact energy that needed to break the concrete includes two parts: the energy to break the matrix and the energy to pull out the fiber reinforcements. Under impact loading, the impact velocity was extremely fast and the loading time was extremely short. A failure mode of pulverization could occur under impact loading at high impact velocity, which is different from a local failure mode under static compressive loading. Randomly oriented fiber reinforcements can form a network structure in concrete. The internal structure of concrete, including fiber geometry, spacing, and quantity, can have a combined effect on the dynamic properties. A good balanced effect associated with these parameters can provide satisfactory mechanical properties for the composite materials. Generally, for a given amount of fiber reinforcement with single type, the longer the fiber reinforcement is, the less the fiber number is and the larger the fiber spacing is [38]. The contribution from the longer length of long fiber reinforcements in the L2S0 mixture would compensate those from the higher fiber spacing and the less fiber number, and vice versa for the L0S2 mixture. This eventually made the dynamic properties of the L2S0 and L0S0 
mixtures comparable.
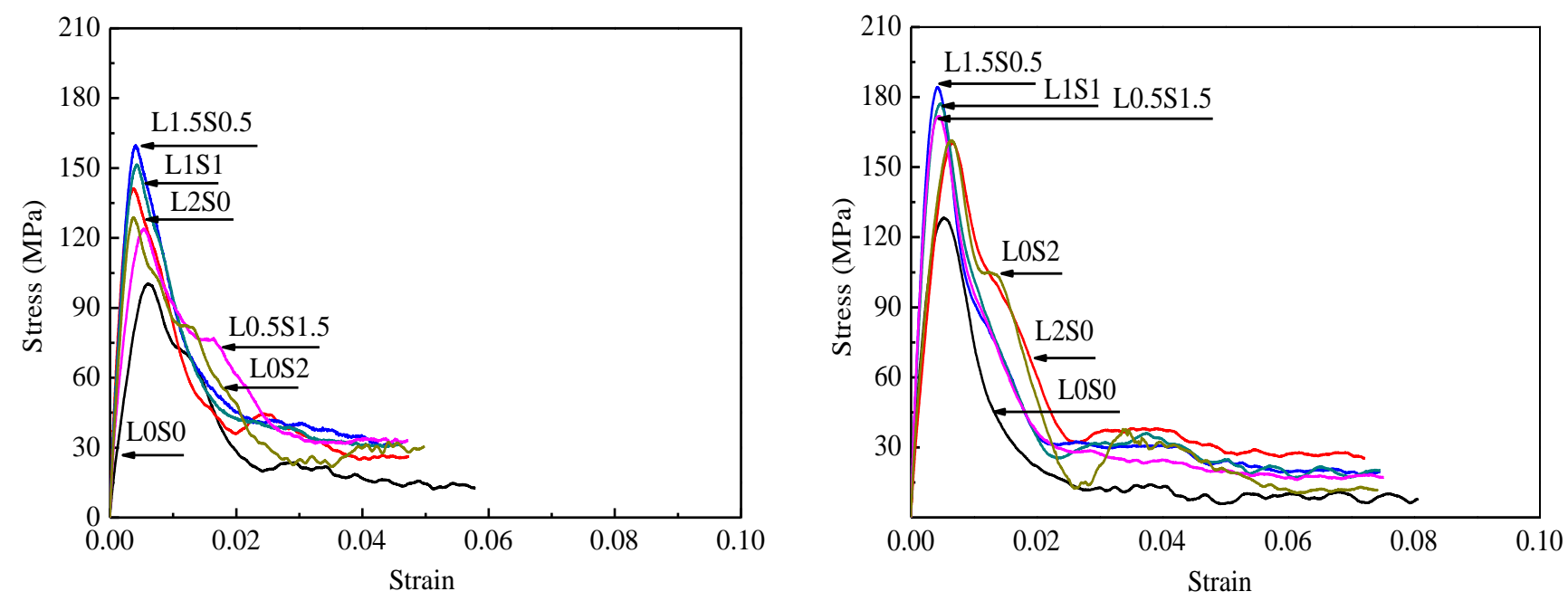

(a) $8.9 \mathrm{~m} / \mathrm{s}$

(b) $11.7 \mathrm{~m} / \mathrm{s}$

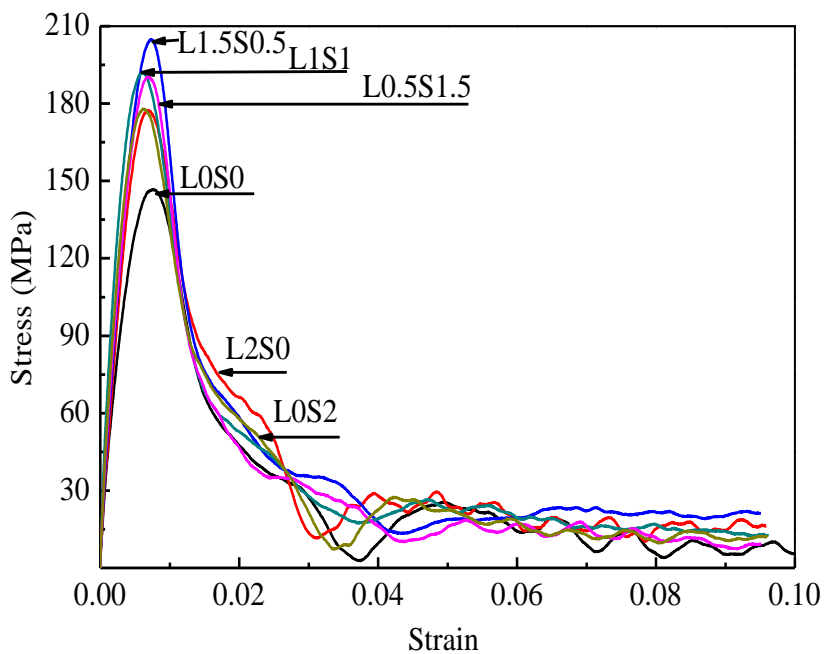

(c) $13.9 \mathrm{~m} / \mathrm{s}$

Fig. 7 Effects of hybrid fiber reinforcements on dynamic compression stress-strain curves of UHPC at 28 $\mathrm{d}$

Table 3 also summarizes the toughness or fracture energy of UHPC, which can be expressed as the area surrounded by the stress-strain curve to a strain of 0.04 . The use of steel fiber reinforcement significantly increased the dynamic compressive toughness. The L1.5S0.5 mixture again showed the highest toughness, which increased by $54.5 \%$ and $33.9 \%$ at the impact velocities of 8.9 and $13.9 \mathrm{~m} / \mathrm{s}$, respectively. With the increase of short fiber reinforcement volume, the toughness decreased. 


\section{Discussion}

The results above showed that the use of single type of fiber reinforcement and hybrid fiber reinforcements significantly improved the static compressive and flexural properties, as well as the dynamic compressive properties of UHPC. The L1.5S0.5 mixture obtained the highest static and dynamic compressive properties. However, with the increase of short fiber reinforcement content, these properties decreased.

As we know, there existed intrinsically weak zones, such as micro-cracks and pores, in UHPC, as shown in Fig. 9. The propagation of micro-cracks can be initiated at the weak zones. This can lead to crack tip stress concentration under external forces. To explain the reason for enhanced strength of a composite material associated with fiber reinforcements, Romualdi et al. [38, 39] proposed a model of crack restraining mechanism, as shown in Fig. 8. It was assumed that continuous fiber reinforcements are evenly distributed in the matrix along the loading direction. A crack with radius of $a$ is surrounded by four fiber reinforcements with a fiber spacing of $S$. Under tensile loading, the region of the crack around the fiber reinforcements can produce cohesive force distribution, as shown in Fig. 8(b). The cohesive force at the crack tip can yield reverse stress field. This can reduce the degree of stress concentration and restrain the propagation of cracks, and hence improving the strength. However, with further increase in the stress, the micro-cracks can propagate into macro-cracks and eventually lead to the failure of concrete members.

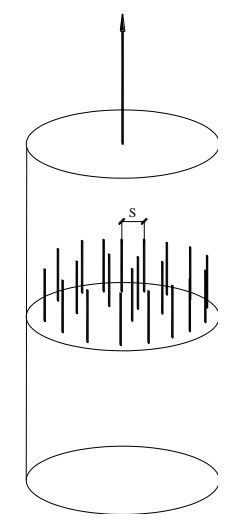

(a)

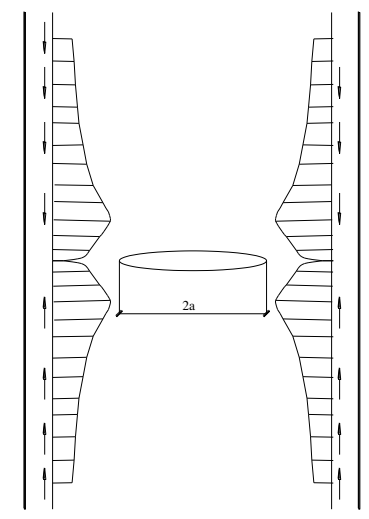

(b)

Fig. 8 Crack restraining mechanism of fiber reinforcements [38, 39] 
When hybrid fiber reinforcements were incorporated, the combined effect associated with short and long fiber reinforcements at different length levels could be exerted, as shown in Fig. 9. The initiated micro-cracks can be restrained by short fiber reinforcements. When the micro-cracks propagate into macro-cracks under further loading, the short fiber reinforcements around the cracks are gradually pulled out and the load is mainly sustained by the long fiber reinforcements. This ensures that more time and energy are needed to damage the concrete.

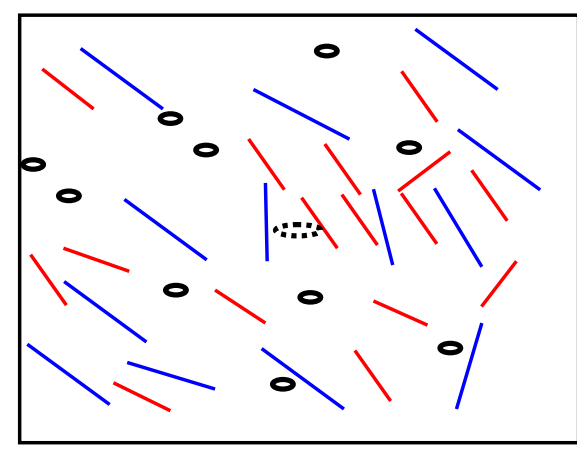

Stage I - no fiber action. Microcracking initiated at weak zones of concrete.

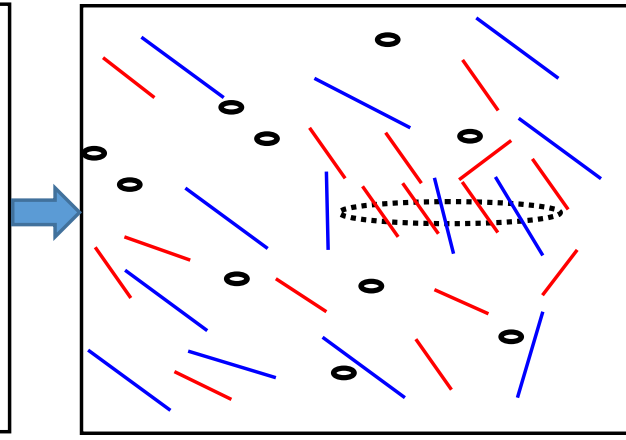

Stage II - action of short fibers. Propagation of micro-cracks.

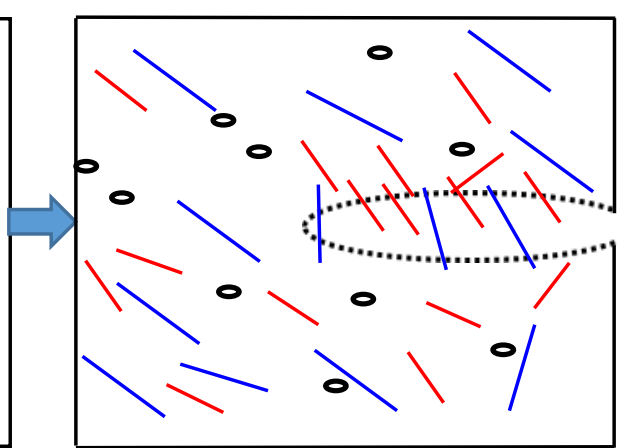

Stage III - action of long fibers. Formation of macro-cracks and eventually cracking of concrete.

Fig. 9 Crack control mechanism for UHPC with hybrid steel fiber reinforcements

The L2S0 and L0S2 mixtures with the single type of fiber reinforcement demonstrated similar dynamic compressive properties, which were different from static compressive properties. This is because the impact velocity was extremely fast and the loading time was extremely short under impact loading. A large number of micro- and macro-cracks can be nucleated and enlarged before the limited micro-cracks developed into macro-cracks under impact loading. Moreover, the quality of the structure, such as fiber geometry, spacing, and quantity, can have a combined effect on the mechanical properties of concrete. For a given volume of single type of fiber reinforcement at a certain fiber reinforcement orientation, the longer the fiber reinforcement is, the less the fiber number is and the larger the fiber spacing is. It was reported that the tensile strength decreasd with the increase of the fiber spacing, but increased with the increase of 
the fiber length [40, 41]. Under impact loading, the dynamic properties of UHPC are much more sensitive to the internal strucutre of the composite materials in such a very short time when compared to the static properties. Therefore, only when the combined effect from these parameters reached an optimal state, can the maximum dynamic compressive properties be obtained.

\section{Conclusions}

This study investigated the effects of hybrid steel fiber reinforcements on flowability, static compressive and flexure properties, as well as dynamic compressive behavior of UHPC. A reference UHPC mixture with no fiber reinforcement and five mixtures with a single type of fiber reinforcement or hybrid steel fiber reinforcements at a total content of $2 \%$, by the volume of concrete, were prepared. Based on the results presented in this study, the following conclusions can be drawn:

(1) The use of steel fiber reinforcement significantly reduced the flowability of UHPC mixtures. UHPC with the single type of fiber reinforcement demonstrated lower flowability than those with hybrid fiber reinforcements. Among the five UHPC mixtures with fiber reinforcements, the mixture with $2 \%$ single type of short fiber reinforcements exhibited the worst flowability. For UHPC with hybrid fiber reinforcements, the flowability gradually increased with the increase of the short fiber reinforcement volume.

(2) Fiber hybridization significantly improved the static compressive and flexural properties of UHPC, as well as the dynamic compressive behavior. The use of steel fiber reinforcement could increase the static compressive strength by $20 \%$ to $40 \%$. The L1.5S0.5 mixture demonstrated both the best static and dynamic compressive behaviors. The static compressive and flexural properties of UHPC with $2 \%$ long fiber reinforcements were significantly higher than those with $2 \%$ short fiber reinforcements, while similar dynamic compressive properties were observed. The dynamic compressive properties, including 
peak stress, dynamic increase factor, and fracture energy of UHPC, increased gradually with the increase of the strain rate.

(3) The reinforcing mechanisms of hybrid fiber reinforcements in UHPC were due to the combined strengthening effects from both the short and long fiber reinforcements, which can restrict the crack development at two length scales. Initially, the initiated micro-cracks were restrained by the short fiber reinforcements. With the micro-cracks propagated further, the short fiber reinforcements were pulled out from the matrix while the long fiber reinforcements began to sustain load. This means that more time and energy are needed to crack the concrete compare to that with the single type of fiber reinforcement. Under impact loading, the impact velocity was extremely fast and the loading time was extremely short. The nucleation and enlargement of cracks, lateral confinement from both the contact surface restriction and lateral inertia could contribute to the dynamic compressive behavior.

\section{Acknowledgements}

Financial support from National Science Foundation of China under contract Nos. 51378196 and U1305243 is greatly appreciated.

\section{References}

[1] Richard P, Cheyrezy M. Reactive powder concretes with high ductility and 200-800 MPa compressive strength. ACI Mater J 1994; 144(3): 507-518.

[2] Shi C, Wu Z, Wang D, Xiao J, Huang Z, Fang Z. A review on ultra high performance concrete: Part I. Raw materials and mixture design. Constr Build Mater 2015; 101: 741-751.

[3] Zhang J, Zhao Ya. The mechanical properties and microstructure of ultra-high-performance concrete containing various supplementary cementitious materials. J Sustain Cem Mater 2016: 1-13.

[4] Wu Z, Shi C, Khayat KH, Wan S. Effects of different nanomaterials on hardening and performance of 
ultra-high strength concrete (UHSC). Cem Concr Compos 2016; 70: 24-34.

[5] Park SH, Kim DJ, Ryu GS, Kohb KT. Tensile behavior of ultra high performance hybrid fiber reinforced concrete. Cem Concr Compos 2012; 34(2): 172-184.

[6] Habel K and Gauvreau P. Response of ultra-high performance fiber reinforced concrete (UHPFRC) to impact and static loading. Cem Concr Compos 2008; 30(10): 938-946.

[7] Wang D, Shi C, Wu Z, Xiao J, Huang Z, Fang Z. A review on ultra high performance concrete: Part II. Hydration, microstructure and properties. Constr Build Mater 2015; 96: 368-377.

[8] Tuan NV, Ye G, Breugel KV, Copuroglu O. Hydration and microstructure of ultra high performance concrete incorporating rice husk ash. Cem Concr Res 2011; 41(11): 1104-1111.

[9] Kim DJ, Park SH, Ryu GS, Koh KT. Comparative flexural behavior of hybrid ultra-high performance fiber reinforced concrete with different macro fibers. Constr Build Mater 2011; 25:4144-4155.

[10]Hannawi K, Bian H, Prince-Agbodjan W, Raghavan B. Effect of different types of fibers on the microstructure and the mechanical behavior of ultra-high performance fiber-reinforced concretes. Composites Part B: Eng. 2016; 86: 214-220.

[11]Wu Z, Shi C, He W, Wu L. Effects of steel fiber content and shape on mechanical properties of ultra high performance concrete. Constr Build Mater 2016; 103: 8-14.

[12]Wu Z, Shi C, He W, Wang D. Uniaxial compression behavior of ultra-high performance concrete with hybrid steel fiber. Journal of Materials in Civil Engineering; 2016: 06016017-1-7.

[13]Kwon S, Nishiwaki T, Kikuta T, Mihashi H. Development of ultra-high-performance hybrid fiber-reinforced cement-based composites (with Appendix). ACI Materials Journal 2014; 111(3): 309-318.

[14]Ku H, Cheng YM, Snook C, Baddeley D. Drop weight impact test fracture of vinyl ester composites: micrographs of pilot study. Journal of composite materials 2005; 39(18): 1607-1620. 
[15]Xu Z, Hao H, Li H. Experimental study of dynamic compressive properties of fibre reinforced concrete material with different fibres. Materials \& Design 2012; 33: 42-55.

[16] Wang H, Wang L. Experimental study on static and dynamic mechanical properties of steel fiber reinforced lightweight aggregate concrete. Constr Build Mater 2013; 38: 1146-1151.

[17]Li Q, Meng H. About the dynamic strength enhancement of concrete-like materials in a split Hopkinson pressure bar test. International Journal of Solids and Structures 2003; 40: 343-360.

[18] Mohammadi Y, Carkon-Azad R, Singh SP, Kaushik SK. Impact resistance of steel fibrous concrete containing fibres of mixed aspect ratio. Constr Build Mater 2009; 23: 183-189.

[19]Rong Z, Sun W, Zhang Y. Dynamic compression behavior of ultra-high performance cement based composites. International Journal of Impact Engineering 2010; 37(5): 515-520.

[20]Lai J, Sun W, Lin W, Jin Z. Static and dynamic mechanical behavior of ECO-RPC. Journal of Southeast University. 2005: 2.

[21]Zhang Y, Sun W, Liu S, Jiao C. Preparation of C200 green reactive powder concrete and its static-dynamic behaviors. Cem Concr Compos 2008; 30(9): 831-838.

[22]Chinese national standard. Chinese cement: common portland cement, GB175-2007. Beijing, China, 2007.

[23] Shi C, Wang D, Wu L, Wu Z. The Hydration and microstructure of ultra high-strength concrete with cement-silica fume-slag binder. Cem Concr Compos 2015; 61: 44-52.

[24]Wu Z, Shi C, Khayat KH. Influence of silica fume content on microstructure development and bond to steel fiber in ultra-high strength cement-based materials (UHSC). Cem Concr Compos 2016; 71: 97-109.

[25]Chinese national standard. Test methods for flowability of cement paste, GB2419-2005, Beijing, China, 2005. 
[26]China National Standards. Method of testing cements - determination of strength, GB/T 17671-1999, Beijing, China (in Chinese), 1999.

[27] Yang H, Li J, Huang Y. Study on the mechanical properties of high performance hybrid fiber reinforced cementitious composite (HFRCC) under impact Loading. in Key Engineering Materials. 2015: Trans Tech Publ.

[28]Zhang W. Investigation of microstructure formation mechanism and dynamic mechanical behavior of UHPCC. Ph.D. thesis, Southeast University. Nanjing, December 2012.

[29] Yu R, Spiesz P, Brouwers HJH. Static properties and impact resistance of a green ultra-high performance hybrid fibre reinforced concrete (UHPHFRC): experiments and modeling. Constr Build Mater 2014; 68: 158-171.

[30]Grünewald S. Performance-based design of self-compacting fiber reinforced concrete. Delft, the Netherlands: Delft University of Technology; 2004.

[31]Boulekbache B, Hamrat M, Chemrouk M, Amzianec S. Flowability of fibre-reinforced concrete and its effect on the mechanical properties of the material. Constr Build Mater 2010; 24(9): 1664-1671.

[32]Cotsovos D, Pavlović M. Numerical investigation of concrete subjected to compressive impact loading. Part 1: A fundamental explanation for the apparent strength gain at high loading rates. Computers \& structures 2008; 86(1): 145-163.

[33]Cotsovos D, Pavlović M. Numerical investigation of concrete subjected to compressive impact loading. Part 2: Parametric investigation of factors affecting behaviour at high loading rates. Computers \& structures 2008; 86(1): 164-180.

[34]Bischoff P, Perry S. Compressive behaviour of concrete at high strain rates. Materials and Structures $1991 ; 24(6): 425-450$.

[35]Lee MK, Barr BIG. An overview of the fatigue behavior of plain and fiber reinforced concrete. Cem 
Concr Compos 2004; 26 (4): 299-305.

[36]Wang Y, Wang Z, Liang X, An M. Experimental and numerical studies on dynamic compressive behavior of reactive powder concretes. Acta Mechanica Solida Sinica, 2008; 21(5): 420-430.

[37]Tai Y. Uniaxial compression tests at various loading rates for reactive powder concrete. Theoretical and Applied Fracture Mechanics 2009; 52(1): 14-21.

[38]Romualdi JP, Mandel JA. Tensile strength of concrete affected by uniformly dispersed and closely spaced short length of wire reinforcement. ACI J Proc 1964; 61(6):657-671.

[39]Romualdi JP, Batson GB. Mechanics of crack arrest in concrete, 1963.

[40]Mangat PS. Tensile strength of steel fiber reinforced concrete. Cem Concr Res 1976; 6(2): 245-252.

[41] Shah SP, Rangan BV. Fiber reinforced concrete properties. In ACI Journal Proceedings 1971; 68(2): 126-137. 